\title{
Suppression sebagai Mediator Peranan Emotional Job Demand terhadap Teacher Well-Being
}

\author{
Yuliezar Perwira Dara \\ Program Studi S1 Psikologi, Fakultas Ilmu Sosial, Universitas Brawijaya \\ Jl. Veteran, Malang, Jawa Timur, Indonesia 65145 \\ perwiradara@ub.ac.id \\ Eleonara Vena Agusta \\ Program Studi S1 Psikologi, Fakultas Ilmu Sosial, Universitas Brawijaya \\ Jl. Veteran, Malang, Jawa Timur, Indonesia 65145 \\ vena agusta@student.ub.ac.id \\ Ulifa Rahma \\ Program Studi S1 Psikologi, Fakultas Ilmu Sosial, Universitas Brawijaya \\ Jl. Veteran, Malang, Jawa Timur, Indonesia 65145 \\ ulifa.rahma@ub.ac.id \\ Faizah \\ Program Studi S1 Psikologi, Fakultas Ilmu Sosial, Universitas Brawijaya \\ Jl. Veteran, Malang, Jawa Timur, Indonesia 65145 \\ faizah_hermawan@ub.ac.id
}

\begin{tabular}{ll} 
Infromasi Artikel & \\
\hline Tanggal masuk & $01-10-2020$ \\
Tanggal revisi & $14-01-2021$ \\
Tanggal diterima & $04-02-2021$
\end{tabular}

Kata Kunci:

emotional job demand;

suppression;

teacher well-being
Keywords:

emotional job demand;

suppression;

teacher well-being
Abstrak

\begin{abstract}
Tujuan penelitian ini adalah untuk mengetahui peran emotional job demand terhadap teacher well-being dengan suppression sebagai mediator. Penentuan sampel menggunakan teknik accidental sampling dengan sampel guru di sekolah negeri ataupun swasta, dari berbagai level pendidikan (SD, SMP, SMA/SMK). Responden dalam penelitian ini adalah 565 guru. Alat ukur yang digunakan untuk mengukur emotional job demand adalah skala transadaptasi dari Skala Emotional Job Demand $(\alpha=.65)$, teacher well-being diukur menggunakan skala transadaptasi dari Teacher Well-Being Scale $(\alpha=.87)$, dan suppression yang diukur menggunakan skala transadaptasi dari Emotion Regulation Questionnaire $(\alpha=.73)$. Penelitian ini menggunakan pendekatan kuantitatif dengan jenis penelitian korelasional yang dianalisis dengan analisis process version 3.4.1 oleh Andrew Hayes menggunakan software SPSS Statistics version 26 for windows. Hasil penelitian menunjukkan bahwa suppression memediasi peran emotional job demand terhadap teacher well-being, dengan nilai signifikansi $0,000(\rangle<0,05)$. Terdapat hubungan tidak langsung emotional job demand terhadap teacher well-being melalui suppression.
\end{abstract}

\section{Abstract}

This study aims to determine the role of Emotional Job Demand towards Teacher Well-Being mediated by Suppression. The sample is taken by using Accidental Sampling Technique to the teachers in public or private schools, from various level education (elementary, secondary and vocational high school). The respondents of the current study are 565 teachers. The emotional job demand is measured by using trans-adaptation scale from Emotional Job Demand Scale $(\alpha=.65)$, teacher well-being is measured from Teacher Well-Being Scale $(\alpha=.87)$, and the suppression is from Emotion Regulation Questionnaire $(\alpha=.73)$. It employs quantitative approach with correlational analysis through process version 3.4.1 by Andrew Hayes using SPSS Statistics Software version 26 for Windows. The results of the research indicates that Suppression mediates 
the role of Emotional Job Demand towards Teacher Well-Being, with significance value of 0.000(\rangle$<0.05)$. there is an indirect relationship of emotional job demand to teacher well-being through suppression.

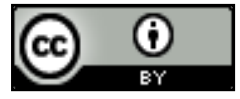

\section{PENDAHULUAN}

Guru merupakan faktor terpenting di sekolah yang berkontribusi pada keberhasilan, kepuasan, dan prestasi belajar siswa (McCallum, Price, Graham, Morrison, 2017). Undang-undang Pendidikan No 14 Tahun 2005 menyebutkan bahwa tugas seorang guru selain mengajar, juga mendidik, mengarahkan, membimbing, melatih, serta mengevaluasi peserta didik. Begitu pentingnya peranan seorang guru dalam meningkatkan pendidikan dengan segala aspeknya.

Akan tetapi pada kenyataannya, pentingnya peranan guru tersebut tidak berbanding lurus dengan kondisi kesejahteraan guru saat ini. Kesejahteraan guru yang sering disoroti di Indonesia adalah dari aspek gaji dan insentif yang diperoleh (Zulkifli, Darmawan, \& Sutrisno, 2014). Akan tetapi, disamping kesejahteraan secara finansial ternyata ada kesejahteraan lain yang masih jarang diangkat, khususnya pada konteks profesi guru di Indonesia, yakni kesejahteraan secara psikologis.

Pernyataan tersebut didukung oleh hasil penelitian terdahulu yang menyebutkan bahwa mengajar memerlukan upaya emosional yang cukup besar (Chang, 2009; Sutton \& Harper, 2009; Yin \& Lee, 2012). Apalagi saat ini guru di Indonesia memiliki beban tersendiri secara emosional dalam mengajar. Hal ini berakar salah satunya dari UndangUndang No. 35 Tahun 2014 tentang Perlindungan Anak, yang justru memberikan kesan imunitas bagi siswa atau keluarga siswa yang merasa menjadi korban ketika mendapat perlakuan disiplin dari gurunya (Affandi, 2016). Salah satunya dilansir dalam surabaya.tribunnews.com, seorang guru di Sulawesi Selatan dipenjara lantaran dianggap melakukan tindakan pendisiplinan dengan cara yang kurang menyenangkan pada siswanya. Hal ini menyebabkan guru merasa memiliki tuntutan untuk senantiasa memberikan perlakuan yang menyenangkan dan dapat diterima oleh siswa dan orang tuanya.

Data Teacher Wellbeing Index United Kingdom pada tahun 2018 yang melaporkan bahwa $67 \%$ tenaga kependidikan mengalami stres dalam pekerjaannya. Huang, Yin dan Lv (2019) menyebutkan bahwa kondisi wellbeing pada guru akan berdampak pada pengajaran dan memiliki efek lanjutan bagi kesejahteraan dan pengembangan akademik siswa. Pandangan umum yang menyatakan bahwa kesejahteraan guru terkait dengan kesejahteraan siswa (dan sebaliknya) didukung secara empiris pada penelitian (McCallum, dkk 2017). Teacher well-being yang rendah akan berdampak pada turunnya well-being siswa yang diampu. Disebutkan juga bahwa kesejahteraan guru selain dapat berdampak pada prestasi siswa, pada tingkat makro juga dapat berdampak pada kualitas sekolah secara menyeluruh ( McCallum, dkk, 2017).

Teacher well-being didefinisikan sebagai pemenuhan rasa profesional pribadi sebagai seorang guru, pencapaian kepuasan, tujuan serta kebahagiaan yang dibangun oleh guru dalam proses kolaboratif dengan kolega dan siswa (Acton \& Glasgow, 2015). Teacher well-being memiliki tiga faktor, yakni workload well-being (dikaitkan dengan masalah pada level sekolah), organizational well-being, dan student interaction well-being (dikaitkan dengan perilaku siswa) (CluniesRoss, Little, \& Kienhuis, 2008; Collie, Shapka, \& Perry, 2012; Klassen \& Ming, 2011). 
Salah satu strategi dalam meningkatkan teacher well-being adalah pengaturan pada job characteristic (Yin, Huang, \& Wang., 2016a., Jonge \& Dollard, 2001; dan Hakanen, Bakker, dan Schaufeli, 2006) dalam penelitiannya yang menyatakan bahwa job characteristic menjadi prediktor yang penting dan memiliki dampak mendalam bagi teacher well-being. Job characteristic dibagi menjadi dua kategori, yakni job demand dan job resource (Bakker \& Demerouti, 2007). Pada konteks profesi guru di sekolah, job demands yang digunakan adalah emotional job demands (Yin, Huang, \& Lv, 2018).

Upaya emosional yang tinggi dalam mengajar dapat memengaruhi level stress dan well-being guru secara signifikan (Chang, 2009; Sutton \& Harper, 2009; Yin dkk, 2016). Studi yang dilakukan oleh (Jonge, Blanc, Peeters, \& Noordam., 2008) menyebutkan bahwa terdapat hubungan positif antara emotional job demand dengan kelelahan secara emosional pada pekerja

Menariknya, sekalipun well-being dan emotional job demand dianggap cukup untuk menjelaskan hubungan satu sama lain, akan tetapi variabel tersebut dianggap masih mengabaikan personal resource atau faktor individu (Yin dkk., 2016). Padahal, pendekatan psikologis mengasumsikan bahwa perilaku manusia dihasilkan dari interaksi antara faktor lingkungan dan pribadi (Horn., Taris,., Schaufeli, \& Schreurs, 2004).

Gross (1998) merumuskan personal resource pada profesi guru di sekolah dalam konteks pengaturan emosi atau emotion regulation. Emotion regulation (ER) didefinisikan sebagai proses memodulasi satu atau lebih aspek dari pengalaman atau respons emosional (Gross, 1998).

Gross \& John (2003) mengidentifikasi dua jenis strategi regulasi emosi berdasarkan tahapan terjadinya, yakni cognitive reappraisal dan expressive suppression. Reappraisal mengacu pada kemampuan individu untuk secara efisien mengendalikan pandangan mengenai situasi yang dapat menimbulkan emosi dan kemampuan individu untuk beradaptasi terhadap lingkungan. Sedangkan suppression mencerminkan ketidakmampuan individu untuk mengatasi lingkungan yang menuntut emosi, dan karenanya dikaitkan dengan upaya ekstra dan pengorbanan baik secara fisik maupun psikologis (Bakker \& Demerouti, 2014). Saat menggunakan strategi suppression, guru berusaha sedemikian rupa untuk menekan dan menahan ekspresi emosinya ketika mengajar. Yin dkk, (2018) menyatakan bahwa pada emotional job demand yang tinggi, guru cenderung menggunakan strategi suppression dan merasakan kecemasan dan depresi yang lebih tinggi, setelah mengalami gangguan kesehatan.

Setelah pemaparan di atas penulis menyimpulkan bahwa job characteristic yang dalam penelitian ini adalah emotional job demand memiliki peran terhadap teacher well -being, namun emotional job demand belum bisa secara penuh menjelaskan perannya terhadap teacher well-being. Personal resource juga perlu dipertimbangkan memiliki peran terhadap teacher well-being, karena pendekatan psikologis mengasumsikan bahwa perilaku manusia dihasilkan dari interaksi antara faktor lingkungan dan pribadi (Horn, dkk, 2004). Salah satu personal resource yang berkaitan dengan tuntutan emosional pekerjaan atau emotional job demand yang tinggi adalah suppression. Maka suppression dijadikan sebagai mediator dalam penelitian ini (Gross \& John, 2003). Oleh karena itu, penelitian ini ingin meneliti peran emotional job demand terhadap teacher well-being, dengan suppression sebagai variabel mediator. 


\section{METODE}

\section{Desain Penelitian}

Penelitian ini merupakan jenis penelitian kuantitatif yang bertujuan untuk meneliti sampel melalui pengumpulan data dengan menggunakan instrumen penelitian. Metode penelitian yang digunakan adalah kuantitatif korelasional dengan analisis process version 3.4.1 oleh Andrew Hayes (2018) untuk mengetahui peran suppression sebagai mediator. Di dalam model yang diajukan, emotional job demand merupakan variabel independen (X), suppression merupakan variabel mediator $(\mathrm{M})$, dan teacher wellbeing merupakan variabel dependen $(\mathrm{Y})$.

\section{Partisipan}

Populasi dalam penelitian ini adalah guru dari seluruh level pendidikan (SD, SMP, SMA/SMK) di Indonesia, baik dari sekolah negeri maupun sekolah swasta. Penentuan sampel dalam penelitian ini menggunakan teknik accidental sampling. Pengambilan data dilakukan dengan menyebarkan kuesioner secara online melalui link google form maupun menyebarkan secara langsung ke sekolah yang dituju. Total partisipan dalam penelitian ini berjumlah 565 orang guru yang terdiri dari 398 perempuan (70.4\%) dan 167 laki-laki (29.6\%).

\section{Skala Teacher Well-Being}

Skala yang digunakan untuk mengukur teacher well-being adalah skala transadaptasi dari Teacher Well-Being Scale (TWBS) yang diciptakan oleh (Collie, Shapka, Perry, 2015). TWBS terdiri dari 16 aitem favorable yang terbagi menjadi tiga subskala yakni workload well-being $(\alpha=.85)$, organizational wellbeing $(\alpha=.84)$, dan student interaction wellbeing $(\alpha=.82)$. TWBS secara keseluruhan memiliki reliabilitas total sebesar .87. TWBS menggunakan 7-point likert scale (1= Negatif, 2 = Sebagian Besar Negatif, $3=$ Cenderung Negatif daripada Positif, $4=$ Netral, $5=$ Cenderung Positif daripada
Negatif, $6=$ Sebagian Besar Positif, $7=$ Positif). Skor teacher well-being diperoleh dari hasil penjumlahan keseluruhan skor yang berkisar dari 7-112. Total skor yang semakin tinggi menunjukkan teacher well-being yang semakin tinggi.

Tahap uji coba dilakukan dengan menyebarkan instrumen penelitian secara online kepada guru-guru sekolah swasta maupun negeri dengan total responden berjumlah 107 orang guru. Berdasarkan hasil data tahap uji coba, seluruh aitem dalam TWBS memiliki nilai koefisien dalam rentang .507-.789, dengan nilai reliabilitas sebesar .917, sehingga keseluruhan aitem TWBS dapat digunakan dalam tahap penelitian.

\section{Skala Teacher Emotional Job Demand}

Skala yang digunakan untuk mengukur emotional job demand pada guru adalah skala transadaptasi dari Emotional Labor Item yang diciptakan oleh (Wong \& Law, 2002) kemudian diadaptasi oleh (Yin, 2015) menjadi Emotional Job Demand of Teaching Scales agar lebih sesuai dengan konteks profesi guru. Emotional Labor Item yang dikembangkan Wong \& Law, (2002) berjumlah 4 aitem favourable. Yin, 2015) mengadaptasi skala tersebut menjadi Emotional Job Demand of Teaching Scales (EJDTS), menggunakan 4 aitem favourable dari skala sebelumnya yang kemudian diadaptasi dengan menambahkan dan mengganti beberapa kata penjelas agar sesuai dengan konteks profesi guru. Emotional Job Demand of Teaching Scales terdiri dari 4 aitem yang menggunakan 5-point likert scale ( 1 = sangat tidak setuju; 2 = tidak setuju; $3=$ netral, $4=$ setuju; $5=$ sangat setuju). Skor emotional job demand diperoleh dari hasil penjumlahan keseluruhan skor yang berkisar dari 4-20. Skor yang lebih tinggi menunjukkan emotional job demand yang lebih tinggi. 
Tahap uji coba dilakukan dengan menyebarkan instrumen penelitian secara online kepada guru-guru sekolah swasta maupun negeri dengan total responden berjumlah 107 orang guru. Berdasarkan hasil data tahap uji coba, seluruh aitem dalam EJDTS memiliki nilai koefisien dalam rentang .498-.566, sehingga keseluruhan aitem EJDTS dapat digunakan dalam tahap penelitian dengan nilai reliabilitas sebesar .676 .

\section{Skala Emotion Regulation Questionnaire}

Skala yang digunakan untuk mengukur suppression pada guru adalah skala transadaptasi dari Emotion Regulation Questionnaire (ERQ) yang diciptakan oleh Gross (1998). ERQ terdiri dari dua subskala, akan tetapi subskala yang digunakan dalam penelitian ini adalah subskala suppression ( $\alpha$ $=.73$ ). Subskala suppression terdiri dari 4 aitem favourable. ERQ menggunakan 7-point likert scale $(1=$ Sangat tidak setuju, $2=$ Tidak Setuju, $3=$ Agak tidak setuju, $4=$ Netral, $5=$ Agak setuju, $6=$ Setuju, $7=$ Sangat setuju).

Tahap uji coba dilakukan dengan menyebarkan instrumen penelitian secara online kepada guru-guru sekolah swasta maupun negeri dengan total responden berjumlah 107 orang guru. Berdasarkan hasil data tahap uji coba, seluruh aitem dalam ERQ (Suppression) memiliki nilai koefisien dalam rentang .381- .605, sehingga keseluruhan aitem ERQ (Suppression) dapat digunakan dalam tahap penelitian dengan nilai reliabilitas sebesar .757 .

\section{Teknik Analisis Data}

Data akan dianalisis menggunakan analisis process modeling versi 3.4.1 oleh Andrew Hayes (2018) pada software SPSS Statistics version 26 for windows.

\section{Hasil}

Hasil dari penelitian ini pada jalur a menyatakan bahwa terdapat peran positif emotional job demand $(\mathrm{M}=16.84, \mathrm{SD}=2.189)$ terhadap suppression $(\mathrm{M}=20.87, \mathrm{SD}=4.053)$. Hasil analisis memiliki makna bahwa emotional job demand memiliki peran sebanyak $8,9 \%$ terhadap peningkatan suppression. Peran emotional job demand terhadap suppression dalam penelitian ini tidak besar karena memang disebutkan dalam penelitian terdahulu oleh Gross, \& John, (2003); Krause, Dasiner, \& Neuhauser (1998) bahwa terdapat beberapa hal yang juga dapat memengaruhi regulasi emosi (yang dalam hal ini adalah suppression), antara lain: kognitif, orang di sekitar (keluarga dan teman sebaya), usia dan jenis kelamin, religiusitas dan spiritualitas, serta budaya setempat. Penelitian Yin (2015) yang menjelaskan bahwa pada guru, emotional job demand mencakup beberapa hal yang meliputi tuntutan kemampuan untuk bisa menjadi tetap tenang dan positif sepanjang hari dan mampu membangun hubungan yang sehat

\begin{tabular}{|c|c|c|c|c|c|c|c|c|}
\hline \multicolumn{9}{|c|}{ Tabel 1. Hasil Uji Hipotesis } \\
\hline \multirow{3}{*}{ Antecedent } & \multicolumn{8}{|c|}{ Consequent } \\
\hline & \multicolumn{4}{|c|}{ M (Suppression) } & \multicolumn{4}{|c|}{ Y (Teacher Well-Being) } \\
\hline & & Coeff. & $\mathrm{SE}$ & $\mathrm{p}$ & & C oeff. & $\mathrm{SE}$ & $\mathrm{p}$ \\
\hline $\begin{array}{l}\mathrm{X} \text { (Emotional Job } \\
\text { Demand) }\end{array}$ & $\mathrm{a}$ & .2559 & .0754 & .0000 & $c^{\prime}$ & .1758 & .3185 & .0000 \\
\hline M (Suppression) & - & - & - & - & $\mathrm{b}$ & .1338 & .1720 & .0016 \\
\hline \multirow[t]{3}{*}{ Constant } & im & 12.8874 & 1.2813 & .0000 & by & 57.8384 & 5.6801 & .0000 \\
\hline & \multicolumn{4}{|c|}{$\mathbf{R}^{2}=.0655$} & \multicolumn{4}{|c|}{$\mathbf{R}^{2}=.0608$} \\
\hline & \multicolumn{4}{|c|}{$\mathrm{F}=39.4568, \mathrm{p}=.0000$} & \multicolumn{4}{|c|}{$\mathrm{F}=18.2030, \mathrm{p}=.0000$} \\
\hline
\end{tabular}


antara guru dengan siswa. Hal ini sejalan dengan definisi serta penerapan suppression dalam konteks pekerjaan guru di sekolah. Suppression merupakan strategi yang muncul sebagai respon dari proses emosionalgeneratif, yang digunakan seseorang untuk menekan emosi yang keluar (Gross, 1998). Emotional job demand biasanya menyebabkan perasaan tidak menyenangkan ketika seseorang merasa emosinya berada di luar kendali (Grandey, 2000), oleh karena itu seorang guru akan cenderung berupaya untuk menekan ekspresi emosi yang dirasakan. Dalam penelitiannya, Yin (2015) menyatakan bahwa emotional job demand dalam mengajar berhubungan dengan kebutuhan guru untuk mengelola emosi. Yin, dkk (2018) pada penelitiannya juga menyimpulkan bahwa, ketika dihadapkan dengan tuntutan emosional pekerajaan yang tinggi, guru cenderung menggunakan strategi suppression (berusaha menekan emosinya) dan merasa lebih cemas.

Hasil analisis dari jalur $b$ menyatakan bahwa terdapat peran positif suppression $(\mathrm{M}=20.87, \mathrm{SD}=4.053)$ terhadap teacher wellbeing $(\mathrm{M}=91.50, \mathrm{SD}=16.486)$, yang berarti semakin seseorang menekan ekspresi emosinya, maka well-beingnya semakin tinggi. Padahal menurut beberapa referensi acuan dan kajian Gross, \& John, (2003) menyatakan bahwa strategi suppression berasosiasi dengan fungsi interpersonal yang buruk dan berkorelasi negatif dengan wellbeing. Guru yang terbiasa menekan emosi atau melakukan suppression memiiki resiko yang lebih tinggi mengalami kelelahan secara emosional dan merasa kurang puas terhadap pekerjaan yang dilakukan (Yin, dkk., 2016). Hasil ini berbeda dengan jurnal terdahulu karena dalam beberapa penelitian disebutkan bahwa terdapat faktor budaya yang memengaruhi seseorang dalam mengekspresikan emosi, yang pada akhirnya dapat memengaruhi well-being-nya. Ford, Mauss dan Gruber (2015) dalam hasil penelitiannya menjelaskan bahwa regulasi emosi (reappraisal dan suppression) dipengaruhi oleh faktor budaya. Penelitian tersebut juga menyatakan bahwa budaya Asia Timur (mis. Jepang atau Cina; Asia Amerika) cenderung relatif saling tergantung antar individu, sedangkan budaya Eropa (mis. Eropa utara atau barat; Eropa-Amerika) cenderung relatif independen. Pernyataan tersebut juga didukung oleh penelitian lain yang diakukan oleh Gore \& Cross (2010) dan Markus \& Kitayama (2010) yang menyatakan bahwa kelompok budaya Barat cenderung memiliki self-construal individualistis, yang mana cenderung merasa independen dari orang lain, menghargai otonomi, kemajuan diri, serta menempatkan diri sebagai titik rujukan utama untuk mengarahkan perilaku dan emosi. Sebaliknya, pada kelompok budaya non-Barat, termasuk budaya Asia Timur, lebih cenderung menganut self-construal kolektif, di mana memandang diri bergantung pada orang lain.

Dijelaskan oleh hasil penelitian Butler, Lee, dan Gross (2009) bahwa terdapat perbedaan hubungan antara emosi dan perilaku ekspresif dengan respon fisiologis pada masyarakat Eropa-Amerika dan Asia. Budaya Eropa Amerika menganggap tingkat ekspresif yang tinggi sebagai tanda-tanda kompetensi serta kelayakan untuk disenangi dalam kehidupan sosial, sedangkan menekan perilaku emosional dikaitkan dengan peningkatan respons fisiologis dan berkurangnya afiliasi. Berbeda dengan kebudayaan di Asia, Matsumoto (1993) dalam penelitiannya menyebutkan bahwa masyarakat Asia menilai ekspresi negatif yang ditunjukkan pada orang lain sebagai sikap yang kurang tepat. Pada penelitian berikutnya di tahun 2008, Matsumoto, dkk menyebutkan bahwa strategi suppression diikuti oleh penilaian ulang yang memungkinkan individu untuk memilih ekspresi emosi yang tepat untuk menjaga ketertiban sosial dan hubungan interpersonal. 
Hasil penelitian ini didukung oleh Markus \& Kitayama (2010) yang menyatakan bahwa tradisi budaya Asia cenderung menghargai pengendalian diri dan perhatian emosional pada orang lain (bukan diri sendiri). Mendukung pernyataan tersebut, Butler dkk (2009) serta Ford dan Mauss (2015) dalam penelitiannya menyatakan bahwa dalam budaya yang menghargai keterkaitan, seperti kelompok masyarakat Asia, cenderung muncul preferensi untuk melakukan suppress -ion karena dapat mengurangi risiko mengganggu harmoni kelompok dengan mengurangi dampak keadaan emosi negatif pada orang lain. Butler dkk (2009) dalam penelitiannya juga menegaskan bahwa strategi suppression yang dilakukan oleh masyarakat Asia memerlukan pengorbanan fisiologis yang lebih rendah dibandingkan pada masyarakat Amerika-Eropa, dan dengan demikian berasosiasi negatif dengan berkurangnya kesehatan mental, termasuk didalamnya kepuasan hidup yang rendah dan depresi (Soto, Perez, dan Hoon Kim, 2011).

Kesehatan mental dan kepuasan hidup merupakan bagian dari aspek kesejahteraan atau well-being. Well-being oleh Ryan \& Deci (2011) didefinisikan sebagai keterbukaan, keterlibatan, dan fungsi yang sehat. Pada konteks profesi guru, kesejahteraan atau well-being sering disebut dengan istilah teacher well-being. Acton, dkk (2015) mendefinisikan teacher well-being sebagai pemenuhan rasa profesional pribadi sebagai seorang guru, pencapaian kepuasan, tujuan serta kebahagiaan yang dibangun oleh guru dalam proses kolaboratif dengan kolega dan siswa. Akan tetapi, definisi kesejahteraan khususnya kesejahteraan guru di berbagai negara bisa jadi berbeda. Hal ini dibuktikan oleh Benevene, Wong, Fiorilli, dan De Stasio (2018) dalam penelitiannya yang menyatakan bahwa terdapat perbedaan definisi kesejahteraan guru pada guru-guru dari 2 negara yang dijadikan subjek penelitian.
Hasil penelitian tersebut menunjukkan bahwa pada guru di Italia definisi kesejahteraan guru atau teacher well-being yang terpenuhi adalah ketika pengawasan, kondisi kerja, hubungan dengan rekan kerja, sifat pekerjaan, dan komunikasi terpenuhi dengan baik. Sedangkan pada guru di Hongkong, teacher well-being dikatakan terpenuhi ketika gaji dan promosinya terpenuhi dengan baik. Oleh karena itu dapat disimpulkan bahwa definisi dari teacher well-being pada setiap daerah atau budaya bisa berbeda-beda. Di Indonesia, definisi kesejahteraan guru atau teacher wellbeing dikatakan oleh Surya (2004) memiliki kaitan erat dengan kepuasan kerja. Kepuasan ini dilaterbelakangi oleh beberapa faktor, salah satunya adalah hubungan antar pribadi.

Jika dilihat lebih dekat lagi pada karakteristik subjek penelitian yakni guru di Indonesia, mayoritas subjek penelitian ini adalah guru yang mengajar di pulau Jawa (84,3\%). Mulder (1985) dalam bukunya menyebutkan bahwa bersikap terus terang, apalagi dalam konteks perasaan-perasaan yang cenderung negatif, dianggap sebagai sikap yang "tidak Jawa", tidak beradab, dan menunjukkan sikap yang tidak menghargai tatanan yang baik. Pernyataan ini didukung oleh ungkapan Jawa yang mengatakan "ngono ya ngono, ning aja ngono" yang artinya "barangkali kau memang benar, tapi jangan pakai cara seperti itu”. Senada dengan pendapat Suseno (1993), disebutkan bahwa sikap suka berpura-pura atau dalam Bahasa Jawa disebut dengan ber-ethok-ethok memang merupakan salah satu ciri yang menonjol pada orang Jawa. Sikap ini dipelihara oleh orang Jawa sebagai upaya untuk menjaga harmoni atau keserasian dan menghindari konflik dalam kehidupan sosial (Harmaini, 2011). Semakin dapat mengendalikan diri dengan baik, semakin orang Jawa merasa dirinya mampu terlibat dalam perwujudan keharmonisan dan keserasian hidup sosial. Oleh karena itu, orang Jawa 
tidak merasa bahwa suppression merupakan beban atau tuntutan yang merugikan kondisi emosional dan mentalnya, yang pada akhirnya dapat mengarah pada turunnya wellbeing.

Hasil analisis terakhir, melalui jalur c' mendukung hipotesis penelitian ini. Suppress -ion memiliki pengaruh yang signifikan dalam memediasi hubungan antara emotional job demand dengan teacher well-being. Pengaruh langsung emotional job demand terhadap teacher well-being menjadi lebih kecil setelah mengontrol suppression $\left(\mathrm{c}^{\prime}<\mathrm{c}\right)$. Meskipun secara angka output analisis dapat diartikan bahwa suppression dapat memediatori peran emotional job demand terhadap teacher well-being secara baik, namun peran emotional job demand terhadap teacher well-being pada penelitian ini berbeda dengan landasan teori atau penelitian terdahulu yang menyatakan bahwa arah peran dari emotional job demand ke teacher wellbeing adalah negatif.

Hasil penelitian (Yin dkk., 2018) menyatakan bahwa pada emotional job demand yang tinggi, guru cenderung menggunakan strategi suppression dan merasakan kecemasan dan depresi yang tinggi, yang diikuti dengan penurunan kesejahteraan dan kesehatan. Hasil studi lain dari Yin dkk (2016) juga menyatakan bahwa emotional job demand secara signifikan meningkatkan kelelahan emosional karyawan dan mengurangi kepuasan kerja mereka. Hasil penelitian tersebut juga menarik kesimpulan bahwa emotional job demands memiliki korelasi yang lebih kuat dengan teacher well-being (pada tingkat yang rendah), ketika guru menggunakan strategi suppression. Akan tetapi, penelitian Crawford, LePine, \& Rich (2010) menyatakan bahwa emotional job demand memiliki dua dimensi, bukan hanya sebagai rintangan namun juga sebagai bentuk tantangan. Dikatakan sebagai rintangan ketika emotional job demand ini menghambat pencapaian tujuan dan mengganggu fungsi terkait pekerjaan, sedangkan dikatakan sebagai tantangan ketika emotional job demand memiliki efek positif pada motivasi dan meningkatkan peluang untuk pencapaian pribadi (Webster, Beehr, dan Christiansen, 2010). Penelitian lain mengatakan bahwa efek dari emotional job demand pada wellbeing tidak berdiri sendiri melainkan bergantung pada variabel lain, seperti dukungan sosial (Jonge \& Dormann, 2006) dan kontrol pribadi (Grandey, Fisk, \& Steiner, 2005). Hal ini didukung oleh DeNoyelles, Hornik, \& Johnson, 2014) yang mengatakan bahwa bahkan dalam kondisi tuntutan yang menantang, seorang guru dengan self-eficacy yang tinggi justru bisa merasa berhasil dalam memenuhi tuntutannya. Perasaan berhasil inilah yang nantinya dapat meningkatkan teacher well-being (Acton dkk., 2015).

Teacher well-being juga dapat dikaitkan dengan kompetensi guru sebagai seorang agen pembelajaran. Menurut Peraturan Pemerintah No. 19 tahun 2005, disebutkan beberapa kompetensi yang harus dimiliki guru sebagai agen pembelajaran, khususnya berkenaan dengan kehidupan sosial yakni: kompetensi kepribadian (berkaitan dengan kemampuan personal yang mantap, stabil, dewasa, arif, dan berwibawa), kompetensi sosial (berkenaan dengan kemampuan guru untuk berkomunikasi dan bergaul secara efektif dengan siapapun). Tuntutan sosial tersebut yang dijalankan oleh guru sesuai dengan budaya yang berlaku akan membawa guru pada perasaan puas dan berhasil karena dapat memenuhi tuntutan kompetensi yang dibebankan kepadanya. Kembali lagi pada pembahasan soal kesejahteraan guru atau teacher well-being oleh Surya (2004) yang menyatakan bahwa kesejahteraan guru erat kaitannya dengan kepuasan kerja, yang dilaterbelakangi oleh beberapa faktor, salah 
satunya hubungan antar pribadi. Oleh karena itu dapat disimpulkan bahwa perasaan puas dan berhasil yang dirasakan guru lantaran dapat memenuhi tuntutan kompetensinya khususnya secara sosial dan emosional dapat meningkatkan well-being seorang guru.

\section{KESIMPULAN}

Hasil analisis data yang dilakukan menghasilkan kesimpulan antara lain: Emotional job demand memiliki peran positif terhadap suppression, sehingga meningkatkan emotional job demand juga dapat meningkatkan suppression. Suppression memiliki peran negatif terhadap teacher wellbeing, sehingga dengan meningkatnya suppression, maka teacher well-being akan menurun. Suppression dapat memediatori peran emotional job demand terhadap teacher well-being, namun perannya tidak lebih besar dari pada peran emotional job demand terhadap teacher well-being secara langsung (tanpa mediator).

Peneliti selanjutnya disarankan untuk lebih berhati-hati lagi dalam penggunaan skala, khususnya dalam penggunaan skala likert. Disarankan untuk membuat skala likert yang mudah dipahami oleh responden, agar tidak terjadi kerancuan ketika menjawab. Selain itu juga disarankan untuk memperhati -kan konteks tujuan penelitian dan konteks dari skala yang akan digunakan, agar data yang didapat dari skala bisa sesuai dengan tujuan awal penelitian.

Penelitian ini diharapkan dapat menjadi suatu pembuktian bahwa emotional job demand memiliki peran terhadap suppression, yang akhirnya juga berperan terhadap teacher well-being. Oleh karena itu, penting bagi pihak pimpinan sekolah untuk memperhatikan beban kerja guru sehingga bisa tercapai kesejahteraan guru yang baik, yang pada akhirnya juga dapat memengaruhi kinerja guru dan kemajuan pendidikan.

\section{DAFTAR RUJUKAN}

Acton, R., \& Glasgow, P. (2015). Teacher wellbeing in neoliberal contexts: A review of the literature. Australian Journal of Teacher Education, 40(8), 99$114 . \quad$ https://doi.org/10.14221/ ajte. $2015 \mathrm{v} 40 \mathrm{n} 8.6$

Acton, R., Glasgow, P., Acton, R., \& Glasgow, P. (2015). Teacher wellbeing in neoliberal contexts : a review of the literature 40(8).

Affandi, A. (2016). Dampak pemberlakuan Undang-Undang. Hukum Samudra Keadilan, 11, 196-208.

Bakker, A. B., \& Demerouti, E. (2007). The Job Demands-Resources model: state of the art. 22(3), 309-328. https:// doi.org/10.1108/02683940710733115

Bakker, A. B., \& Demerouti, E. (2014). Job Demands - Resources Theory. III (Work and Wellbeing: Wellbeing: A Complete Reference Guide), 1-28. https:// doi.org/10.1002/9781118539415.wbwe 11019

Benevene, P., Ho, Y., Wong, P., Fiorilli, C., \& Stasio, S. De. (2018). A CrossNational Comparison on Subjective Well-Being of Kindergarten Teachers : Hong Kong and Italy 9(December). https://doi.org/10.3389/ fpsyg.2018.02626

Butler, E. A., Lee, T. L., \& Gross, J. J. (2009). Does expressing your emotions raise or lower your blood pressure? Journal of Cross-Cultural Psychology, 40, 510-517.

Chang, M. (2009). An appraisal perspective of teacher burnout: Examining the emotional work of teachers. Educ Psychol Rev, 21, 193-218. https:// doi.org/10.1007/s10648-009-9106-y

Collie, R. J., Shapka, J. D., \& Perry, N. E. 
(2012). School climate and social emotional learning: Predicting teacher stress, job satisfaction, and teaching efficacy. Journal of Educational Psychology, 104(4), 1189-1204. https:// doi.org/10.1037/a0029356

Collie, R. J., Shapka, J. D., Perry, N. E., \& Martin, A. J. (2015). Teacher wellbeing: Exploring its components and a practice- oriented scale. Journal of Psychoeducational Assessment, 33(8), 744-756. https:// doi.org/10.1177/0734282915587990

Crawford, E. R., Lepine, J. A., \& Rich, B. L. (2010). Linking job demands and resources to employee engagement and burnout: A theoretical extension and meta-analytic test. Journal of Applied Psychology, 95, 834 - 848. http:// dx.doi.org/10.1037/a0019364

DeNoyelles, A., Hornik, S. R., \& Johnson, R. D. (2014). Exploring the dimensions of self-efficacy in virtual world learning: environment, task, and content. Journal of Online Learning and Teaching. 10(2), 255-271.

Ford, B. Q., Mauss, I. B., \& Gruber, J. (2015). Valuing Happiness Is Associated With Bipolar Disorder. 15 (2), 211-222.

Gore, J. S., \& Cross, S. E. (2010). Relational self-construal moderates the link between goal coherence and wellbeing. Self and Identity, 9, 41-61. https://

doi.org/10.1080/15298860802605861

Grandey, A. A. (2000). Emotion regulation in the workplace: A new way to conceptualize emotional labor. Journal of Occupational Health Psychology, 5 (1), 95-110. https:// doi.org/10.1037//1076-8998.S.1.9S

Grandey, A. A., Fisk, G. M., \& Steiner, D. D.
(2005). Must "service with a smile" be stressful? The moderating role of personal control for American and French employees. Journal of Applied Psychology, 90(5), 893-904. https:// doi.org/10.1037/0021-9010.90.5.893

Gross, J. J. (1998). Antecedent- and response -focused emotion regulation : Divergent Consequences for experience, expression, and physiology. Journal of Personality and Social Psychology, 74 (1), 224-237.

Gross, J. J., \& John, O. P. (2003). Individual differences in two emotion regulation processes Implications for affect, relationships, and well-being. Journal of Personality and Social Psychology. Journal of Personality and Social Psychology, 85(2), 348-362.

Hakanen, J. J., Bakker, A. B., \& Schaufeli, W. B. (2006). Burnout and work engagement among teachers. Journal of School Psychology, 43, 495-513. https://doi.org/10.1016/ j.jsp.2005.11.001

Horn, J. E., Taris, T. W., Schaufeli, W. B., \& Schreurs, P. J. G. (2004). The structure of occupational well-being: A study among Dutch teachers. Journal of Occupational and Organizational Psychology.

Huang, S., Yin, H., \& Lv, L. (2019). Job characteristics and teacher well-being: The mediation of teacher selfmonitoring and teacher self-efficacy. Educational Psychology, 39(3), 313331. https:// doi.org/10.1080/01443410.2018.15438 55

Jonge, J. De., Dormann, C., Janssen, P.P.M., Dollard, M. F., Landeweerd, J.A., Nijhuis, J.N. (2001). Testing reciprocal relationships between job 
characteristics and psychological wellbeing: A cross-lagged structural equation model. Journal of Occupational and Organizational Psychology, 74, 29-46.

Jonge, J. De, \& Dormann, C. (2006). Stressors, Resources, and strain at work: A longitudinal test of the triplematch principle. Journal of Applied Psychology 91(5), 1359-1374. https:// doi.org/10.1037/0021-9010.91.5.1359

Jonge, J. De,. Banc, P. M. Le., Peeters, M. C. W., \& Noordam, H. (2008). Emotional job demands and the role of matching job resources : A cross-sectional survey study among health care workers. International Journal of Nursing Studies, 45, 1460-1469. https:// doi.org/10.1016/j.ijnurstu.2007.11.002

Klassen, R. M., \& Chiu, M.M. (2011). The occupational commitment and intention to quit of practicing and pre-service teachers: Influence of self-efficacy, job stress, and teaching context. Contemporary Educational Psychology, 36 (2001), 114-129. https:// doi.org/10.1016/

j.cedpsych.2011.01.002

Krause, N., Dasinger, L. K., \& Neuhauser, F. (1998). Modified work and return to Work: A Review of the Literature. Springer, 8, 113-139.

Markus, H. R., \& Kitayama, S. (2010). Cultures and Selves: A Cycle of Mutual Constitution. Perspective on Psychology. 5(4), 420-430. https:// doi.org/10.1177/1745691610375557

Matsumoto, D. (1993). Ethnic differences in affect intensity, emotion judgments , display rule attitudes, and self-reported emotional expression in an american sample. Motivation and Emotion, 17(2), 107-123.
McCallum, F., Price, D., Graham, A., Morrison, A. (2017). Teacher WellBeing. Teacher Well-Being: a review of the literatur. https:// doi.org/10.4324/9780203465400

Mulder, N. (1985). Pribadi dan masyarakat di Jawa. Yogyakarta: Penerbit Sinar Harapan. 192

Ryan, R. M., \& Deci, E. L. (2011). A SelfDetermination theory perspective on social , institutional, cultural, and economic supports for autonomy and their importance for well-being. Human Autonomy in Cross-Cultural Context, Cross-Cultural Advancements in Positive Psychology, 45-64. https:// doi.org/10.1007/978-90-481-9667-8

Soto, J.A., Perez, C. R., Kim, Y.H., Lee, E. A., \& Minnick, M. R. (2011). Is expressive suppression always associated with poorer psychological functioning? a cross-cultural comparison between European Americans and Hong Kong Chinese. Emotion, 11(6), 1450-1455. https:// doi.org/10.1037/a0023340

Surya, M. (2004). Psikologi pembelajaran dan pengajaran (pp. 73-74).

Suseno, F.M. (1993). Etika Jawa Magnis (pp. 257-264).

Webster, J. R., Beehr, T. A., \& Christiansen, N. D. (2010). Toward a better understanding of the effects of hindrance and challenge stressors on work behavior. Journal of Vocational Behavior, 76(2010), 68-77. https:// doi.org/10.1016/j.jvb.2009.06.012

Wong, C.S., \& Law, K. S. (2002). The effects of leader and follower emotional intelligence on performance and attitude: An exploratory study. The Leadership Quarterly, 13, 243-274. 
Yin, H., \& Lee, J. C. (2012). Be passionate, but be rational as well : Emotional rules for Chinese teachers ' work. Teaching and Teacher Education, 28(1), 56-65. https://doi.org/10.1016/ j.tate. 2011.08 .005

Yin, Hongbiao. (2015). The effect of teachers , emotional labour on teaching satisfaction: Moderation of emotional intelligence. Teachers and Teaching: Theory and Practice, March, 37-41. https:// doi.org/10.1080/13540602.2014.99548 2

Yin, H., Huang, S., \& Lv, L. (2018). A multilevel analysis of job characteristics, emotion regulation, and teacher well-being: A Job DemandsResources Model. Frontiers in Psychology, 9(NOV), 1-13. https:// doi.org/10.3389/fpsyg.2018.02395

Yin, H., Huang, S., \& Wang, W. (2016). Work environment characteristics and teacher well-being: The mediation of emotion regulation strategies. International Journal of Environmental Research and Public Health Article, 13 (907), 1-16. https://doi.org/10.3390/ ijerph13090907

Zulkifli, M., Darmawan, A., \& Sutrisno, E. (2014). Motivasi kerja, sertifikasi, kesejahteraan dan kinerja guru. Persona: Jurnal Psikologi Indonesia, 3(02), 148-155. 